\title{
Mechanistic Role of MicroRNA in Cancer Chemoprevention by Nonsteroidal Anti-inflammatory Drugs
}

\author{
Ruixia Ma • Bin Yi • Gary A. Piazza • Yaguang Xi
}

Published online: 11 January 2015

(C) Springer International Publishing AG 2015

\begin{abstract}
Over the past several decades, studies have documented the cancer chemopreventive activity of nonsteroidal anti-inflammatory drugs (NSAIDs) by lowering incidence and slowing down progression of malignant disease, which consequently lead to decline of cancer-related mortality and improvement of disease progression-free survival (PFS). Inhibition of cyclooxygenase (COX) has been primarily believed to be the key mechanism responsible for anticancer activity of NSAIDs, while the serious toxicity caused by COX inhibitory effect reduces the enthusiasm to use NSAIDs as chemopreventive agents in the clinic. Recently, more and more studies demonstrate that non-COX inhibitory mechanisms may, at least partially, account for anticancer properties of NSAIDs, which potentially support the indication of NSAIDs on cancer chemoprevention. MicroRNAs (miRNAs) are a set of noncoding and small RNA molecules with the master regulatory effect on over $30 \%$ human genes through the posttranscriptional and translational modulation. Although miRNAs have been reported to be involved in many normal and pathological processes including cell proliferation, apoptosis, differentiation, as well as tumorigenesis; their roles in NSAIDs' properties of cancer chemoprevention have not yet been studied exclusively. Here, we will review the prior studies reporting the interactions between miRNAs and COX/ non-COX pathways with the intent to provide new insights into the molecular mechanisms responsible for NSAIDs' anticancer activity.
\end{abstract}

This article is part of the topical collection on miRNA and cancer prevention and therapeutic agents

R. Ma $\cdot$ B. Yi $\cdot$ G. A. Piazza $\cdot$ Y. Xi $(\bowtie)$

University of South Alabama Mitchell Cancer Institute, 1660

Springhill Ave, Mobile, AL 36604, USA

e-mail: xi@health.southalabama.edu
Keywords MiRNAs $\cdot$ NSAIDs $\cdot$ Cancer $\cdot$ Cyclooxygenase $(\mathrm{COX}) \cdot \mathrm{COX}-2 \cdot$ Chemoprevention

\section{Introduction}

According to the latest world cancer report, the global burden of cancer rose to an estimate of 14 million new cases per year, which is predicted to reach 22 million annually within the next 20 years [1]. Although cancer burden grows at an alarming pace, fortunately, cancer prevention plays a crucial role in combating the tidal wave of cancer that we have seen coming across the world over the past few decades. In particular, cancer chemoprevention is referred to reversion, suppression, or prevention of either the initial phase of carcinogenesis or the development of neoplastic cells to cancer by the use of natural, synthetic, or biologic substances $[2,3]$. Nonsteroidal anti-inflammatory drugs (NSAIDs) are a chemically diverse group of agents with anti-inflammatory, antipyretic, and/or analgesic properties. Intriguingly, numerous reports support the anti-neoplastic role of NSAIDs in various human tumors, such as colon, breast, lung, prostate, gastric, and bladder cancer [4-6], although the molecular mechanisms by which NSAIDs prevent tumorigenesis and progression have not been understood completely.

MiRNAs are a class of noncoding small (averaging 20 nucleotides) RNA molecules that can negatively regulate gene expression through repressing translation or affecting mRNA stability [7]. It is estimated that over one third of human genes are targeted and regulated by miRNAs [8]. Because of their key roles in regulation of gene expression, miRNAs have been recognized as the "master" regulators of human gene expression, which are responsible for a multitude of normal 
biological and pathological events, such as differentiation, proliferation, cell growth, apoptosis, and tumorigenesis. In human cancer, miRNAs have been widely reported to be involved in tumor pathogenesis, progression, metastasis, prognosis, and responsiveness of patients to chemotherapy. However, its role in cancer chemoprevention has not been studied systematically. Given that miRNAs are recognized as the master regulators of gene expression and alternation of their putative targets are almost involved in all cellular events, miRNAs can be hypothesized as a set of mechanistic mediators accounting for the mechanistic basis of NSAIDs' pleiotropic antineoplastic activities. To support this assumption, we will summarize the published literatures by focusing on the studies that can potentially provide insights into the mechanistic role of miRNAs in cancer chemoprevention by NSAIDs.

\section{Cancer Chemoprevention of NSAIDs}

NSAIDs are referred to a chemically diverse family of drugs that are usually used for treatment of a variety of inflammatory conditions and/or relief of pain caused by diseases, such as arthritis. They are emerging as a particularly valuable class of chemopreventative agents based on their documented anti-tumor properties. Previous studies reported that the use of NSAIDs was associated with a reduced colorectal cancer risk and incidence [9, 10], and long-term use of low-dose selective NSAIDs, such as aspirin, could reduce risk for colorectal and other solid tumors $[6,11,12 \cdot \bullet]$, which support the potential application of NSAIDs in cancer chemoprevention. Over the past a few decades, numerous studies have explored the mechanisms by which NSAIDs prevent tumorigenesis and progression, while demonstration of cyclooxygenase (COX) inhibition is one of the most significant achievements in the field of research.

Cyclooxygenase has two informs referring to COX-1 and COX-2, which are named as principle targets of NSAIDs but with the distinct expression patterns and bioactivities [13]. COX-1 is a "housekeeping" gene that is commonly found in the kidney, stomach, and platelets. It is responsible for the process of producing physiological prostaglandins (PGs), which are of importance for COX-1's homeostatic functions, such as to maintain the renal blood flow, mediate normal platelet function, and regulate the microcirculation of the gastric mucosa. COX-2 is mainly expressed in macrophages, leukocytes, and fibroblasts [14], but its expression levels are restricted in normal tissues. Intriguingly, COX-2 can be elevated by the inflammatory reaction. Pro-inflammatory cytokines, such as interleukin 1(IL-1) and tumor necrosis factor-alpha (TNF- $\alpha$ ), have been shown to induce the expression of COX-2 [15].

Aside from the phenotypes in inflammation, COX-2 increases in some types of human cancers, such as colon cancer [16]. The resistance to apoptosis, or programmed cell death may be involved in the mechanisms underlying the association between COX-2 overexpression and tumorigenic potential [15]. Given the evidence in support of its signature in tumorigenesis and cancer progression, $\mathrm{COX}-2$ has been named as one of the key targets accounting for anticancer activity of NSAIDs [17, 18]. This conclusion is also supported by the studies showing that COX-1/COX-2 specific inhibitors and non-selective COX inhibitors could not only inhibit tumor cell growth, but also reduce tumor metastasis [19]. A recent preclinical study reported that NSAIDs with the properties inhibiting COX-2 could effectively prevent tumor metastasis and disease progression through antiangiogenic mechanisms in vivo [20], which further supports that the use of NSAIDs is a viable option for cancer patients with advanced malignant disease.

Regardless of anticancer efficacy, NSAIDs are actually not recommended to be used for cancer chemoprevention in the clinic because COX inhibition is often associated with potentially fatal gastrointestinal, renal, and cardiovascular toxicity [21]. However, numerous studies have reported that COX inhibition does not fully account for its antineoplastic activity [22-28], which implies that alternative mechanisms can be targeted to develop safer and more efficacious derivatives. For example, Piazza's group has made a significant contribution in studies of the non-COX inhibitory mechanism by characterizing cyclic guanosine monophosphate (cGMP) phosphodiesterase (PDE) as a novel target of sulindac for breast and colon cancer prevention [29-32, 33••]. They found that sulindac sulfide (SS) can inhibit PDE5 and certain other cGMP degrading isozymes, which increase intracellular cGMP levels that activate protein kinase $\mathrm{G}(\mathrm{PKG})$ in breast cancer cells and that this activity is COX-independent [30, 31]. These studies provide strong evidence in support of the COX-independent properties of sulindac leading to safer and more efficacious derivatives for human cancers. Moreover, $\mathrm{Wnt} / \beta$-catenin, AMPK, NF- $\mathrm{kB}$, and PPAR $\gamma$ signaling pathways are reported to be involved in non-COX anticancer activities of selective NSAIDs [34-38]. Based on these previous accomplishments, we think that better understanding of the mechanistic basis accounting for NSAIDs' anticancer activity should be a key step to develop novel, safe, and effective agents to prevent tumorigenesis and cancer progression, while the master regulators of gene expression, miRNAs, may be involved in these underlying mechanisms.

\section{MiRNAs and Cancer}

MiRNAs are of single-stranded, non-coding sequences and naturally occurring small RNA molecules that bind to 3'-UTR of target genes to repress their expression at the posttranscriptional and translational levels [39, 40]. Approximately $30 \%$ of all human genes are regulated by miRNAs in which each is capable of mediating the expression of several 
hundreds of cognate messenger RNA targets simultaneously, and over one third of human genes appear to be conserved miRNA targets [8]. Approximately, a couple of thousands of human miRNAs have been identified that are involved in many biological processes including apoptosis, proliferation, differentiation, cell death, immune reactions, tumorigenesis, and metastasis $[41,42]$.

\section{MiRNA Biogenesis}

The biogenesis of miRNAs is similar to other RNA molecules starting from DNA transcription. MiRNAs are primarily transcribed by RNA polymerase II (pol II) as long primary transcripts that are known as primary-miRNAs (pri-miRNAs), and these transcripts are often spliced and located within their intronic segments. In general, primiRNAs contains multiple miRNA sequences and within itself can fold back into stem-loop precursors of approximately 60-80 nucleotides, known as the miRNAs precursor (pre-miRNAs). During the process, the hairpins are recognized and excised from pri-miRNAs in the nucleus by the microprocessor complex consisting of the RNase III enzyme Drosha and its binding partner DGCR8 [43]. After being exported to the cytoplasm by the nuclear export factor-exportin 5 rapidly [44, 45] pre-miRNAs are further processed to double-stranded miRNA duplexes by Dicer, a member of the RNase III superfamily of bidentate nucleases. The final process to mature miRNAs is through a large protein complex, named the RNA-induced silencing complex (RISC), which includes the Argonaute (Ago) proteins as the core components. The strand binding with the RISC stably becomes the mature miRNA with the function regulating gene expression at the post-transcriptional and/or translational levels; whereas the other strand, also known as the passenger strand or miRNA ${ }^{*}$, is degraded accordingly [42, 45-47]. The process of miRNA biogenesis and their central function in regulation of gene expression are exhibited in Fig. 1.

\section{Anti-neoplastic Activity of MiRNAs}

MiRNAs play a key regulatory role in the pathological processes in addition to their curial functions in normal cellular events, such as development, cell proliferation, cell differentiation, and apoptosis [41, 48, 49]. To date, more than 15,000 literatures have been recorded in PubMed under the key words of "miRNA and cancer." The first direct study reporting the significance of miRNAs in cancer was published by Calin et al. a decade ago [50]. They found that a 30-kb deletion within the chromosome 13q14 where miR-15 and miR-16 are located is correlated to the incidence of B-cell chronic lymphocytic leukemia (B-CLL) [50].

Following this pilot study, scientists and physicians have made significant progress on studies of miRNA and human diseases including cancer in basic, translational, and clinical researches. For example, Song et al. reported that miR-200b could inhibit tumor cell growth and migration by suppressing ZEB1 and the sequential augment of E-cadherin in vivo [51]. Lu et al. used the bead-based flow cytometric miRNA expression profiling method to implement a systematic expression analysis of 217 mammalian miRNAs in 334 human samples. Their results showed the aberrant expression patterns of oncogenic and tumor suppressor miRNAs in human tumor tissues when compared to normal tissues, which suggested the
Fig. 1 MiRNA biogenesis and mechanism of action in regulation of gene expression

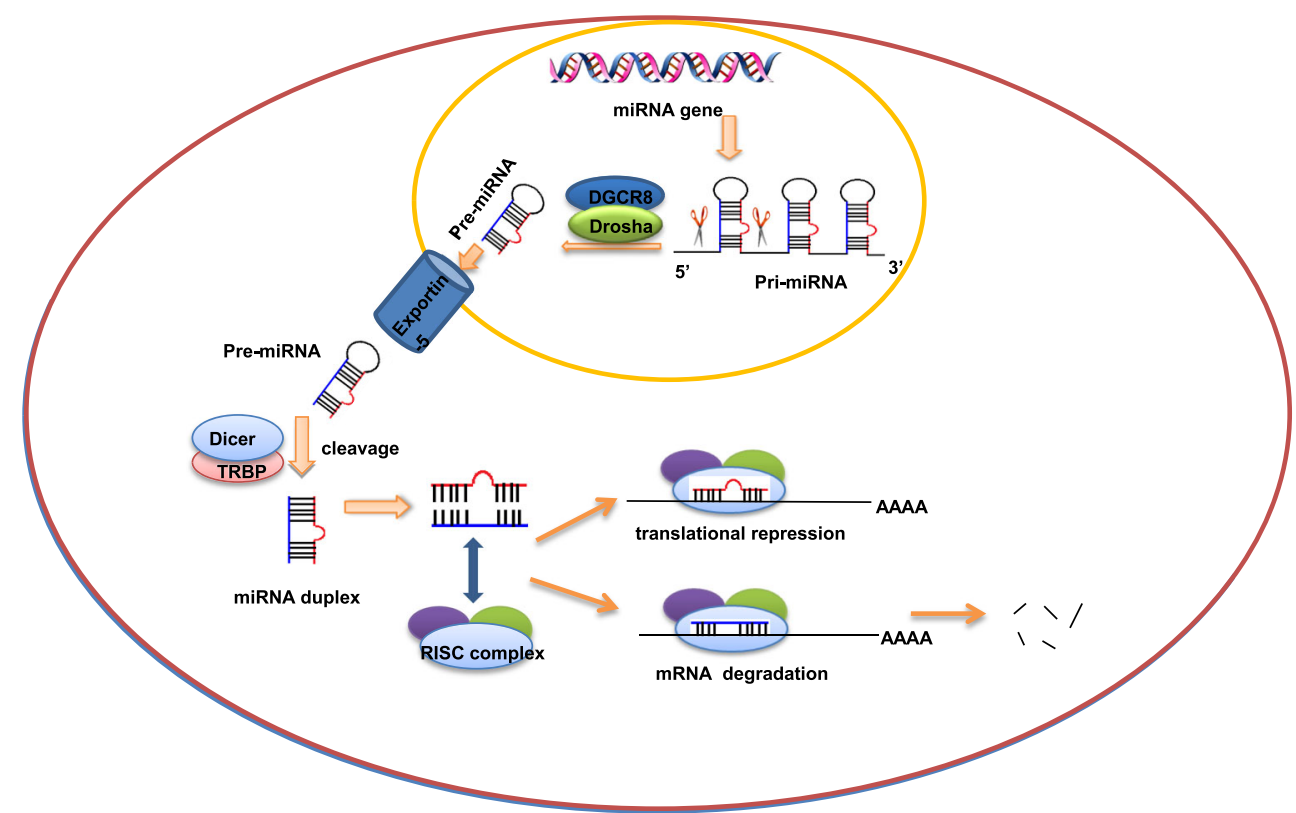


potential of miRNA as biomarkers for disease diagnosis [52]. The prognostic values of miRNAs in cancer have also been identified in variety of human tumors. For example, in addition to miR-200c that was reported to be a novel prognostic marker in colorectal cancer by our group [53], miRNAs are also found to target the tumor suppressor genes to promote hematopoietic stem cell self-renewal and transformation [54]. In this study, overexpression of miR-22 inhibiting the tumor suppressor TET2 was demonstrated to be responsible for the poor clinical outcomes in myelodysplastic syndrome (MDS) and leukemia [54]. A recent study reported that the assays featured by multiple miRNA signatures can not only discriminate hepatocellular carcinoma (HCC) from normal tissues, but also can predict HCC patients' survival [55]. Development of bioinformatics and technology provides new insights into study of miRNA and human diseases. For example, the cancer miRNA regulatory network (http://cmrn.systemsbiology.net) is built to show the interaction of miRNAs with 2,240 genes based on 46 cancer transcriptome profiling studies. Searching this database is able to quickly identify candidate miRNAs that correlate to selective diseases.

\section{MiRNAs, a New Player in Cancer Chemoprevention by NSAIDs}

NSAIDs have been proposed as chemopreventive agents for variable human tumors, although the mechanisms of cancer chemoprevention by NSAIDs have not been understood completely [56, 57]. As discussed above, COX and nonCOX inhibitory pathways have been documented as two of the most important mechanisms accounting for the basis of action [56]; however, it has not been concluded that these known pathways can fully address the pleiotropic activities of NSAIDs in cancer chemo prevention. Given the properties of targeting multiple genes by which miRNAs influence variety of signaling pathways, impaired miRNA regulation can contribute to the development of cancer and other diseases.

COX-2 has been reported to play an important role in tumorigenesis [58], and overexpression of COX-2 in varieties of cancers has been demonstrated, such as breast cancer [59], colon cancer [58], lung cancer [60], prostate cancer [61, 62], and other tumors [63, 64]. As discussed above, COX-2 is named as one of the most important targets responsible for the anticancer activity of NSAIDs. Thereby, any miRNAs that are able to trigger COX2 may be involved in the COX dependent mechanism of NSAIDs anticancer activity. However, there are a few studies reporting the inhibition of COX-2 signaling by miRNAs [65-67], but only one of them is related to human cancer [67]. A latest study reported that miR-101 was downregulated in the cisplatin-resistant human bladder cancer cells T24/CDDP, while overexpression of miR-101 rescued the anticancer activity of cisplatin. The luciferase reporter assay demonstrated that miR101 could directly target 3 '-UTR of COX-2 gene and silence of COX-2 by siRNAs could mimic the phenotype led by overexpression of miR-101 [67]. In addition, a study demonstrated that celecoxib, a COX-2 selective inhibitor, could regulate the expression of miR-29c in human gastric cancer cells [68]. In this study, miR-29c showed the tumor suppressor signature, whereas COX-2 inhibition of miR-29c might be responsible for progression of gastric cancer [68].

The NSAID sulindac has been shown to display strong efficacy for the treatment of precancerous lesions in patients with familial adenomatous polyposis (FAP) to reduce adenoma size and numbers by as much as $60-70 \%$ [69]. These observations are consistent with a large number of preclinical studies that have shown the ability of sulindac and other NSAIDs to inhibit tumorigenesis in various experimental animal models involving either early or late stage diseases [70-73]. In one of our the recent publications, we reported that sulindac sulfide (SS) can potently inhibit the invasion of human breast and colon tumor cells at concentrations less than those required to inhibit tumor cell growth in vitro [74••]. This inhibitory activity by SS was found to be associated with significant changes in miRNA expression, implying that miRNAs may be involved in the pleiotropic anticancer activity of sulindac against tumor progression and metastasis $[74 \bullet \cdot]$. Using the microarray analysis, we found that SS treatment could alter the expression of 132 miRNAs (17 up and 115 down) in human HCT116 colon tumor cells, in which several have been previously reported to promote tumor metastasis and invasion, such as miR-10b, miR-17, miR-21, and miR9. We further demonstrated that the mechanism of NSAIDs in control of these oncogenic miRNAs is through the NF- $k B$ signaling. When SS inhibits the entrance of NF- $\mathrm{KB}$ to the nucleus, its transcription activity upregulating these oncogenic miRNAs is thereby decreased [74••]. Thus, our results support a non-COX-inhibitory mechanism involving miRNAs that is responsible for anti-invasive activity of sulindac. The mechanistic basis of miRNA accounting for anticancer activity of NSAIDs is summarized in Fig. 2.

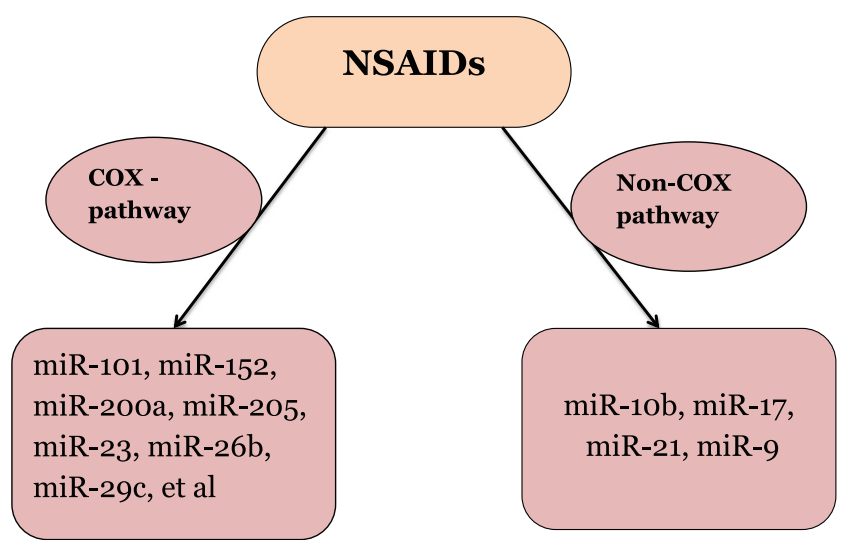

Fig. 2 Mechanistic basis of miRNA accounting for anticancer activity of NSAIDs 


\section{Summary}

The characteristic of miRNAs has been implicated in the pathogenesis of variable human cancer types and their potential as diagnostic markers, therapeutic targets, and prognostic indicators have been intensively studied [75]; however, its mechanistic role in cancer chemoprevention by NSAIDs has not been well studied. Given the signature targeting over $30 \%$ human genes that are involved in most of cellular events, miRNAs have potentials to address the pleiotropic antineoplastic activities of NSAIDs. In support of this assumption, our recent study reported that downregulation of selective oncogenic miRNAs by sulindac through NF- $\mathrm{BB}$ signaling is responsible for anti-invasive activity of this NSAID, which is a novel non-COX inhibitory mechanism. In addition, a recent review article by Yiannakopoulou also raises that targeting epigenetic processes and miRNA expression by aspirin and other NSAIDs might be a novel strategy with potential efficacy for cancer therapy and prevention [76]. Therefore, better understanding of the mechanistic roles of miRNAs in cancer chemoprevention by NSAIDs will provide invaluable insights into development of novel anticancer agents with improved efficacy and safety.

Acknowledgments This study was supported by an American Cancer Society Research Scholar Grant (RSG-13-265-01-RMC, to Yaguang Xi) and NIH/NCI R21 Grants (5R21CA160280 and 1R21CA182754 to Yaguang $\mathrm{Xi}$ ). We sincerely apologize to those whose work was not cited due to time and space constraints.

\section{Compliance with Ethics Guidelines}

Conflict of Interest Ruixia Ma, Bin Yi, Gary A. Piazza, and Yaguang $\mathrm{Xi}$ declare that they have no conflict of interest.

Human and Animal Rights and Informed Consent This article does not contain any studies with human or animal subjects performed by any of the authors.

\section{References}

Papers of particular interest, published recently, have been highlighted as:

- Of major importance

1. Stewart B, Wild CP (2014) World Cancer Report 2014. 16

2. Zhang L, Ren X, Alt E, Bai X, Huang S, Xu Z, et al. Chemoprevention of colorectal cancer by targeting APC-deficient cells for apoptosis. Nature. 2010;464(7291):1058-61. doi:10.1038/ nature08871.

3. Sporn MB, Dunlop NM, Newton DL, Smith JM. Prevention of chemical carcinogenesis by vitamin $\mathrm{A}$ and its synthetic analogs (retinoids). Fed Proc. 1976;35(6):1332-8.

4. Smalley W, Ray WA, Daugherty J, Griffin MR. Use of nonsteroidal anti-inflammatory drugs and incidence of colorectal cancer: a population-based study. Arch Intern Med. 1999;159(2):161-6.
5. Sandler RS, Halabi S, Baron JA, Budinger S, Paskett E, Keresztes $\mathrm{R}$, et al. A randomized trial of aspirin to prevent colorectal adenomas in patients with previous colorectal cancer. N Engl J Med. 2003;348(10):883-90. doi:10.1056/NEJMoa021633.

6. Jonsson F, Yin L, Lundholm C, Smedby KE, Czene K, Pawitan Y. Low-dose aspirin use and cancer characteristics: a population-based cohort study. Br J Cancer. 2013;109(7):1921-5. doi:10.1038/bjc. 2013.411.

7. Friedman RC, Farh KK, Burge CB, Bartel DP. Most mammalian mRNAs are conserved targets of microRNAs. Genome Res. 2009;19(1):92-105. doi:10.1101/gr.082701.108.

8. Lewis BP, Burge CB, Bartel DP. Conserved seed pairing, often flanked by adenosines, indicates that thousands of human genes are microRNA targets. Cell. 2005;120(1):15-20. doi:10.1016/j.cell. 2004.12.035.

9. Ruder EH, Laiyemo AO, Graubard BI, Hollenbeck AR, Schatzkin A, Cross AJ. Non-steroidal anti-inflammatory drugs and colorectal cancer risk in a large, prospective cohort. Am J Gastroenterol. 2011;106(7):1340-50. doi:10.1038/ajg.2011.38.

10. Gurpinar E, Grizzle WE, Piazza GA. NSAIDs inhibit tumorigenesis, but how? Clin Cancer Res. 2014;20(5):1104-13. doi:10.1158/ 1078-0432.CCR-13-1573.

11. Cook NR, Lee IM, Zhang SM, Moorthy MV, Buring JE. Alternateday, low-dose aspirin and cancer risk: long-term observational follow-up of a randomized trial. Ann Intern Med. 2013;159(2): 77-85. doi:10.7326/0003-4819-159-2-201307160-00002.

12.• Trabert B, Ness RB, Lo-Ciganic WH, Murphy MA, Goode EL, Poole EM, et al. Aspirin, nonaspirin nonsteroidal anti-inflammatory drug, and acetaminophen use and risk of invasive epithelial ovarian cancer: a pooled analysis in the Ovarian Cancer Association Consortium. J Natl Cancer Inst. 2014;106(2):djt431. doi:10.1093/ jnci/djt431. This clinical study demontrated that daily use of lowdose aspirin can postentially reduce the risk of ovarian cancer, which supports the new indication of this "old" FDA approved generic drug in cancer prevention.

13. Kelley KA, Ho L, Winger D, Freire-Moar J, Borelli CB, Aisen PS, et al. Potentiation of excitotoxicity in transgenic mice overexpressing neuronal cyclooxygenase-2. Am J Pathol. 1999;155(3):9951004. doi:10.1016/S0002-9440(10)65199-1.

14. Sonoshita M, Takaku K, Oshima M, Sugihara K, Taketo MM. Cyclooxygenase-2 expression in fibroblasts and endothelial cells of intestinal polyps. Cancer Res. 2002;62(23):6846-9.

15. Crofford LJ. COX-1 and COX-2 tissue expression: implications and predictions. J Rheumatol Suppl. 1997;49:15-9.

16. Ramsay RG, Friend A, Vizantios Y, Freeman R, Sicurella C, Hammett F, et al. Cyclooxygenase-2, a colorectal cancer nonsteroidal anti-inflammatory drug target, is regulated by c-MYB. Cancer Res. 2000;60(7):1805-9.

17. Skopinska-Rozewska E, Piazza GA, Sommer E, Pamukcu R, Barcz E, Filewska M, et al. Inhibition of angiogenesis by sulindac and its sulfone metabolite (FGN-1): a potential mechanism for their antineoplastic properties. Int J Tissue React. 1998;20(3):85-9.

18. Gurpinar E, Grizzle WE, Piazza GA. COX-independent mechanisms of cancer chemoprevention by anti-inflammatory drugs. Front Oncol. 2013;3:181. doi:10.3389/fonc.2013.00181.

19. Kundu N, Fulton AM. Selective cyclooxygenase (COX)-1 or COX2 inhibitors control metastatic disease in a murine model of breast cancer. Cancer Res. 2002;62(8):2343-6.

20. Gately S, Li WW. Multiple roles of COX-2 in tumor angiogenesis: a target for antiangiogenic therapy. Semin Oncol. 2004;31(2 Suppl 7):2-11.

21. Mazhar D, Gillmore R, Waxman J. COX and cancer. QJM. 2005;98(10):711-8. doi:10.1093/qjmed/hci119.

22. Alberts DS, Hixson L, Ahnen D, Bogert C, Einspahr J, Paranka N, et al. Do NSAIDs exert their colon cancer chemoprevention 
activities through the inhibition of mucosal prostaglandin synthetase? J Cell Biochem Suppl. 1995;22:18-23.

23. Elder DJ, Halton DE, Hague A, Paraskeva C. Induction of apoptotic cell death in human colorectal carcinoma cell lines by a cyclooxygenase-2 (COX-2)-selective nonsteroidal antiinflammatory drug: independence from COX-2 protein expression. Clin Cancer Res. 1997;3(10):1679-83.

24. Hanif R, Pittas A, Feng Y, Koutsos MI, Qiao L, Staiano-Coico L, et al. Effects of nonsteroidal anti-inflammatory drugs on proliferation and on induction of apoptosis in colon cancer cells by a prostaglandin-independent pathway. Biochem Pharmacol. 1996;52(2):237-45.

25. Kashfi K, Rigas B. Non-COX-2 targets and cancer: expanding the molecular target repertoire of chemoprevention. Biochem Pharmacol. 2005;70(7):969-86. doi:10.1016/j.bcp.2005.05.004.

26. Piazza GA, Rahm AK, Finn TS, Fryer BH, Li H, Stoumen AL, et al. Apoptosis primarily accounts for the growth-inhibitory properties of sulindac metabolites and involves a mechanism that is independent of cyclooxygenase inhibition, cell cycle arrest, and p53 induction. Cancer Res. 1997;57(12):2452-9.

27. Piazza GA, Rahm AL, Krutzsch M, Sperl G, Paranka NS, Gross PH, et al. Antineoplastic drugs sulindac sulfide and sulfone inhibit cell growth by inducing apoptosis. Cancer Res. 1995;55(14):3110-6.

28. Rigas B, Shiff SJ. Is inhibition of cyclooxygenase required for the chemopreventive effect of NSAIDs in colon cancer? A model reconciling the current contradiction. Med Hypotheses. 2000;54(2):210-5. doi:10.1054/mehy.1999.0023.

29. Piazza GA, Keeton AB, Tinsley HN, Gary BD, Whitt JD, Mathew $\mathrm{B}$, et al. A novel sulindac derivative that does not inhibit cyclooxygenases but potently inhibits colon tumor cell growth and induces apoptosis with antitumor activity. Cancer Prev Res (Phila). 2009;2(6):572-80. doi:10.1158/1940-6207.CAPR-09-0001.

30. Tinsley HN, Gary BD, Keeton AB, Lu W, Li Y, Piazza GA. Inhibition of PDE5 by sulindac sulfide selectively induces apoptosis and attenuates oncogenic Wnt/beta-catenin-mediated transcription in human breast tumor cells. Cancer Prev Res (Phila). 2011;4(8):1275-84. doi:10.1158/1940-6207.CAPR-11-0095.

31. Tinsley HN, Gary BD, Keeton AB, Zhang W, Abadi AH, Reynolds $\mathrm{RC}$, et al. Sulindac sulfide selectively inhibits growth and induces apoptosis of human breast tumor cells by phosphodiesterase 5 inhibition, elevation of cyclic GMP, and activation of protein kinase G. Mol Cancer Ther. 2009;8(12):3331-40. doi:10.1158/1535-7163. MCT-09-0758.

32. Tinsley HN, Gary BD, Thaiparambil J, Li N, Lu W, Li Y, et al. Colon tumor cell growth-inhibitory activity of sulindac sulfide and other nonsteroidal anti-inflammatory drugs is associated with phosphodiesterase 5 inhibition. Cancer Prev Res (Phila). 2010;3(10): 1303-13. doi:10.1158/1940-6207.CAPR-10-0030.

33.• Whitt JD, Li N, Tinsley HN, Chen X, Zhang W, Li Y, et al. A novel sulindac derivative that potently suppresses colon tumor cell growth by inhibiting cGMP phosphodiesterase and beta-catenin transcriptional activity. Cancer Prev Res (Phila). 2012;5(6):822-33. doi:10. 1158/1940-6207.CAPR-11-0559. This research article presented $a$ novel deteritive of sulindac, SBA that lacked COX-2 inhibitory properties but showed improved suppressive effect on human colorectal tumor cells by targeting cGMP phosphodiesterases, which supports that non-COX inhibitory mechanisms are also of importance to address the anticancer activities of NSAIDs.

34. Boon EM, Keller JJ, Wormhoudt TA, Giardiello FM, Offerhaus GJ, van der Neut R, et al. Sulindac targets nuclear beta-catenin accumulation and Wnt signalling in adenomas of patients with familial adenomatous polyposis and in human colorectal cancer cell lines. Br J Cancer. 2004;90(1):224-9. doi:10.1038/sj.bjc.6601505.

35. Chi Y, Li K, Yan Q, Koizumi S, Shi L, Takahashi S, et al. Nonsteroidal anti-inflammatory drug flufenamic acid is a potent activator of AMP-activated protein kinase. J Pharmacol Exp Ther. 2011;339(1):257-66. doi:10.1124/jpet.111.183020.

36. Jiang C, Ting AT, Seed B. PPAR-gamma agonists inhibit production of monocyte inflammatory cytokines. Nature. 1998;391(6662): 82-6. doi:10.1038/34184.

37. Kopp E, Ghosh S. Inhibition of NF-kappa B by sodium salicylate and aspirin. Science. 1994;265(5174):956-9.

38. Sareddy GR, Kesanakurti D, Kirti PB, Babu PP. Nonsteroidal antiinflammatory drugs diclofenac and celecoxib attenuates Wnt/betacatenin/Tcf signaling pathway in human glioblastoma cells. Neurochem Res. 2013;38(11):2313-22. doi:10.1007/s11064-013$1142-9$.

39. Ambros V. The functions of animal microRNAs. Nature. 2004;431(7006):350-5. doi:10.1038/nature02871.

40. Xi Y (2013) MicroRNA: A New Player for Cancer Chemoprevention. J Integr Oncol 2(1). doi:10.4172/2329-6771.1000105

41. Schickel R, Boyerinas B, Park SM, Peter ME. MicroRNAs: key players in the immune system, differentiation, tumorigenesis and cell death. Oncogene. 2008;27(45):5959-74. doi:10.1038/onc. 2008.274.

42. Hwang HW, Mendell JT. MicroRNAs in cell proliferation, cell death, and tumorigenesis. Br J Cancer. 2006;94(6):776-80. doi: 10.1038/sj.bjc.6603023.

43. Kim VN. MicroRNA biogenesis: coordinated cropping and dicing. Nat Rev Mol Cell Biol. 2005;6(5):376-85. doi:10.1038/nrm1644.

44. Yi R, Qin Y, Macara IG, Cullen BR. Exportin-5 mediates the nuclear export of pre-microRNAs and short hairpin RNAs. Genes Dev. 2003;17(24):3011-6. doi:10.1101/gad.1158803.

45. Gregory RI, Chendrimada TP, Cooch N, Shiekhattar R. Human RISC couples microRNA biogenesis and posttranscriptional gene silencing. Cell. 2005;123(4):631-40. doi:10.1016/j.cell.2005.10. 022 .

46. Matranga C, Tomari Y, Shin C, Bartel DP, Zamore PD. Passengerstrand cleavage facilitates assembly of siRNA into Ago2containing RNAi enzyme complexes. Cell. 2005;123(4):607-20. doi:10.1016/j.cell.2005.08.044.

47. Rand TA, Petersen S, Du F, Wang X. Argonaute2 cleaves the antiguide strand of siRNA during RISC activation. Cell. 2005;123(4): 621-9. doi:10.1016/j.cell.2005.10.020.

48. Yang L, Lu X, Liu Y, Lv Z, Chen J, Yu W, et al. Expression analysis of miRNAs in BmN cells. Gene. 2012;505(2):240-5. doi:10.1016/ j.gene.2012.06.018

49. Bukhari SI, Vasquez-Rifo A, Gagne D, Paquet ER, Zetka M, Robert $\mathrm{C}$, et al. The microRNA pathway controls germ cell proliferation and differentiation in C. elegans. Cell Res. 2012;22(6):1034-45. doi:10.1038/cr.2012.31.

50. Calin GA, Dumitru CD, Shimizu M, Bichi R, Zupo S, Noch E, et al. Frequent deletions and down-regulation of micro- RNA genes miR15 and miR16 at 13q14 in chronic lymphocytic leukemia. Proc Natl Acad Sci U S A. 2002;99(24):15524-9. doi:10.1073/ pnas.242606799.

51. Song F, Yang D, Liu B, Guo Y, Zheng H, Li L, et al. Integrated microRNA network analyses identify a poor-prognosis subtype of gastric cancer characterized by the miR-200 family. Clin Cancer Res. 2014;20(4):878-89. doi:10.1158/1078-0432.CCR-13-1844.

52. Lu J, Getz G, Miska EA, Alvarez-Saavedra E, Lamb J, Peck D, et al. MicroRNA expression profiles classify human cancers. Nature. 2005;435(7043):834-8. doi:10.1038/nature03702.

53. Xi Y, Formentini A, Chien M, Weir DB, Russo JJ, Ju J, et al. Prognostic values of microRNAs in colorectal cancer. Biomark Insights. 2006;2:113-21.

54. Song SJ, Ito K, Ala U, Kats L, Webster K, Sun SM, et al. The oncogenic microRNA miR-22 targets the TET2 tumor suppressor to promote hematopoietic stem cell self-renewal and transformation. Cell Stem Cell. 2013;13(1):87-101. doi:10.1016/j. stem.2013.06.003. 
55. Wei R, Huang GL, Zhang MY, Li BK, Zhang HZ, Shi M, et al. Clinical significance and prognostic value of microRNA expression signatures in hepatocellular carcinoma. Clin Cancer Res. 2013;19(17):4780-91. doi:10.1158/1078-0432.CCR-12-2728.

56. Chan TA. Nonsteroidal anti-inflammatory drugs, apoptosis, and colon-cancer chemoprevention. Lancet Oncol. 2002;3(3):166-74.

57. Rao CV, Reddy BS. NSAIDs and chemoprevention. Curr Cancer Drug Targets. 2004;4(1):29-42.

58. Brown JR, DuBois RN. COX-2: a molecular target for colorectal cancer prevention. J Clin Oncol. 2005;23(12):2840-55. doi:10. 1200/JCO.2005.09.051.

59. Singh B, Berry JA, Shoher A, Ayers GD, Wei C, Lucci A. COX-2 involvement in breast cancer metastasis to bone. Oncogene. 2007;26(26):3789-96. doi:10.1038/sj.onc.1210154.

60. Kim GY, Lim SJ, Kim YW. Expression of HuR, COX-2, and survivin in lung cancers; cytoplasmic HuR stabilizes cyclooxygenase-2 in squamous cell carcinomas. Mod Pathol. 2011;24(10):1336-47. doi:10.1038/modpathol.2011.90.

61. Khor LY, Bae K, Pollack A, Hammond ME, Grignon DJ, Venkatesan VM, et al. COX-2 expression predicts prostate-cancer outcome: analysis of data from the RTOG 92-02 trial. Lancet Oncol. 2007;8(10):912-20. doi:10.1016/S1470-2045(07)70280-2.

62. Richardsen E, Uglehus RD, Due J, Busch C, Busund LT. COX-2 is overexpressed in primary prostate cancer with metastatic potential and may predict survival. A comparison study between COX-2, TGF-beta, IL-10 and Ki67. Cancer Epidemiol. 2010;34(3):316-22. doi:10.1016/j.canep.2010.03.019.

63. Ishikawa TO, Jain NK, Herschman HR. Cox-2 gene expression in chemically induced skin papillomas cannot predict subsequent tumor fate. Mol Oncol. 2010;4(4):347-56. doi:10.1016/j.molonc.2010.06. 004.

64. Kulkarni S, Rader JS, Zhang F, Liapis H, Koki AT, Masferrer JL, et al. Cyclooxygenase-2 is overexpressed in human cervical cancer. Clin Cancer Res. 2001;7(2):429-34.

65. Akhtar N, Haqqi TM. MicroRNA-199a* regulates the expression of cyclooxygenase-2 in human chondrocytes. Ann Rheum Dis. 2012;71(6):1073-80. doi:10.1136/annrheumdis-2011-200519.

66. Chakrabarty A, Tranguch S, Daikoku T, Jensen K, Furneaux H, Dey SK. MicroRNA regulation of cyclooxygenase-2 during embryo implantation. Proc Natl Acad Sci U S A. 2007;104(38): 15144-9. doi:10.1073/pnas.0705917104.
67. Bu Q, Fang Y, Cao Y, Chen Q, Liu Y. Enforced expression of miR101 enhances cisplatin sensitivity in human bladder cancer cells by modulating the cyclooxygenase 2 pathway. Mol Med Rep. 2014;10(4):2203-9. doi:10.3892/mmr.2014.2455.

68. Saito Y, Suzuki H, Imaeda H, Matsuzaki J, Hirata K, Tsugawa H, et al. The tumor suppressor microRNA-29c is downregulated and restored by celecoxib in human gastric cancer cells. Int $\mathrm{J}$ Cancer. 2013;132(8):1751-60. doi:10.1002/ijc.27862.

69. Giardiello FM, Hamilton SR, Krush AJ, Piantadosi S, Hylind LM, Celano P, et al. Treatment of colonic and rectal adenomas with sulindac in familial adenomatous polyposis. N Engl J Med. 1993;328(18):1313-6. doi:10.1056/NEJM199305063281805.

70. Beazer-Barclay Y, Levy DB, Moser AR, Dove WF, Hamilton SR, Vogelstein B, et al. Sulindac suppresses tumorigenesis in the Min mouse. Carcinogenesis. 1996;17(8):1757-60.

71. Mahmoud NN, Boolbol SK, Dannenberg AJ, Mestre JR, Bilinski RT, Martucci C, et al. The sulfide metabolite of sulindac prevents tumors and restores enterocyte apoptosis in a murine model of familial adenomatous polyposis. Carcinogenesis. 1998;19(1):87-91.

72. Piazza GA, Alberts DS, Hixson LJ, Paranka NS, Li H, Finn T, et al. Sulindac sulfone inhibits azoxymethane-induced colon carcinogenesis in rats without reducing prostaglandin levels. Cancer Res. 1997;57(14):2909-15.

73. Thompson HJ, Jiang C, Lu J, Mehta RG, Piazza GA, Paranka NS, et al. Sulfone metabolite of sulindac inhibits mammary carcinogenesis. Cancer Res. 1997;57(2):267-71.

74.• Li X, Gao L, Cui Q, Gary BD, Dyess DL, Taylor W, et al. Sulindac inhibits tumor cell invasion by suppressing NF-kappaB-mediated transcription of microRNAs. Oncogene. 2012;31(48):4979-86. doi: 10.1038/onc.2011.655. This research article is for the first time to demonstrate that microRNAs were involved in anti-invasive activity of the NSAID, sulindac in human cancers.

75. Croce CM. Causes and consequences of microRNA dysregulation in cancer. Nat Rev Genet. 2009;10(10):704-14. doi:10.1038/ $\operatorname{nrg} 2634$.

76. Yiannakopoulou E. Targeting epigenetic mechanisms and microRNAs by aspirin and other non steroidal anti-inflammatory agents - implications for cancer treatment and chemoprevention. Cell Oncol (Dordr). 2014;37(3):167-78. doi:10.1007/s13402-0140175-7. 